\title{
Detection of Legionella species, the influence of precipitation on the amount of Legionella DNA, and bacterial microbiome in aerosols from outdoor sites near asphalt roads in Toyama Prefecture, Japan
}

\author{
Jun-ichi Kanatani ${ }^{1{ }^{*}}$, Masanori Watahiki ${ }^{1}$, Keiko Kimata ${ }^{1}$, Tomoko Kato ${ }^{1}$, Kaoru Uchida ${ }^{1}$, Fumiaki Kura ${ }^{2}$,
} Junko Amemura-Maekawa ${ }^{2}$ and Junko Isobe ${ }^{1}$

\begin{abstract}
Background: Legionellosis is caused by the inhalation of aerosolized water contaminated with Legionella bacteria. In this study, we investigated the prevalence of Legionella species in aerosols collected from outdoor sites near asphalt roads, bathrooms in public bath facilities, and other indoor sites, such as buildings and private homes, using amoebic co-culture, quantitative PCR, and 165 rRNA gene amplicon sequencing.

Results: Legionella species were not detected by amoebic co-culture. However, Legionella DNA was detected in 114/151 (75.5\%) air samples collected near roads (geometric mean \pm standard deviation: $1.80 \pm 0.52 \log _{10}$ copies/ $\left.\mathrm{m}^{3}\right)$, which was comparable to the numbers collected from bathrooms [15/21 (71.4\%), 1.82 \pm 0.50$]$ but higher than those collected from other indoor sites [11/30 (36.7\%), $0.88 \pm 0.56](P<0.05)$. The amount of Legionella DNA was correlated with the monthly total precipitation $(r=0.56, P<0.01)$. It was also directly and inversely correlated with the daily total precipitation for seven days $(r=0.21, P=0.01)$ and one day $(r=-0.29, P<0.01)$ before the sampling day, respectively. $16 \mathrm{~S}$ rRNA gene amplicon sequencing revealed that Legionella species were detected in 9/30 samples collected near roads (mean proportion of reads, $0.11 \%$ ). At the species level, L. pneumophila was detected in 2/30 samples collected near roads (the proportion of reads, 0.09 and $0.11 \%$ of the total reads number in each positive sample). The three most abundant bacterial genera in the samples collected near roads were Sphingomonas, Streptococcus, and Methylobacterium (mean proportion of reads; $21.1 \%, 14.6 \%$, and 1.6\%, respectively). In addition, the bacterial diversity in outdoor environment was comparable to that in indoor environment which contains aerosol-generating features and higher than that in indoor environment without the features.
\end{abstract}

\footnotetext{
* Correspondence: junichi.kanatani@pref.toyama.lg.jp

${ }^{1}$ Department of Bacteriology, Toyama Institute of Health, 17-1

Nakataikoyama, 939-0363 Imizu-city, Toyama, Japan

Full list of author information is available at the end of the article
}

(c) The Author(s). 2021 Open Access This article is licensed under a Creative Commons Attribution 4.0 International License, which permits use, sharing, adaptation, distribution and reproduction in any medium or format, as long as you give appropriate credit to the original author(s) and the source, provide a link to the Creative Commons licence, and indicate if changes were made. The images or other third party material in this article are included in the article's Creative Commons licence, unless indicated otherwise in a credit line to the material. If material is not included in the article's Creative Commons licence and your intended use is not permitted by statutory regulation or exceeds the permitted use, you will need to obtain permission directly from the copyright holder. To view a copy of this licence, visit http://creativecommons.org/licenses/by/4.0/ The Creative Commons Public Domain Dedication waiver (http://creativecommons.org/publicdomain/zero/1.0/) applies to the data made available in this article, unless otherwise stated in a credit line to the data. 
Conclusions: DNA from Legionella species was widely present in aerosols collected from outdoor sites near asphalt roads, especially during the rainy season. Our findings suggest that there may be a risk of exposure to Legionella species not only in bathrooms but also in the areas surrounding asphalt roads. Therefore, the possibility of contracting legionellosis in daily life should be considered.

Keywords: Legionella species, Legionellosis, Aerosols, Asphalt roads, Microbiome

\section{Background}

Legionella is the causative agent of Legionnaires' disease, a severe form of legionellosis and a potentially fatal pneumonia [1]. At present, 62 Legionella species have been identified [2], approximately half of which have been demonstrated to be pathogenic to humans, and the majority is considered as potential human pathogens [3]. Legionella species are ubiquitous in natural environments, and they have also been found in artificial environments, such as cooling towers, baths, showers, and decorative fountains [4-7].

Legionellosis can be acquired through the inhalation of aerosolized water contaminated with Legionella [8]. Therefore, aquatic facilities are potential sources of sporadic cases and outbreaks of this disease. According to the National Epidemiological Surveillance of Infectious Diseases, public bath facilities are a major source of Legionella infections in Japan [9]. However, in many cases, the sources of infection remain unknown. The results of our previous study suggested that puddles on asphalt roads can serve as potential environmental reservoirs of L. pneumophila [10]. Several authors have suggested that Legionella present in puddles on roads could be spread by moving cars, which would result in the aerosolization of puddle water, especially on rainy days [11-13]. Recently, several studies have attempted to detect Legionella species in aerosols released from hot tap water in bathrooms, shower water, and compost [14-16]. These studies revealed that Legionella species are present in aerosols derived from these environments. The Coriolis $\mu$, a portable cyclone-based air sampler for liquid medium, has been used to quantify Legionella in bioaerosols by quantitative PCR (qPCR) [14]. However, to date, the prevalence of Legionella species in aerosols from outdoor sites near asphalt roads has not been analyzed.

Typically, conventional plate culture has been used to detect Legionella in clinical and environmental samples. In some cases, amoebic co-culture has been used, because it can resuscitate viable but non-culturable (VBNC) Legionella cells [17] and has a higher sensitivity than plate culture method [18]. In addition, 16S rRNA gene amplicon sequencing has been widely used to detect bacterial pathogens in environmental samples, as metagenomic analysis using 16S rRNA genes is a powerful tool for analyzing microbial communities [19].
The main objective of this study was to determine whether Legionella species present in aerosols derived from outdoor sites near asphalt roads could be a source of Legionella infection. We investigated the prevalence of Legionella species in aerosols from outdoor sites near asphalt roads using amoebic co-culture and qPCR methods. Other types of sampling sites were used and compared; public bathrooms were used as high-risk areas for infection since Legionella can be frequently found here, and other indoor sites, such as buildings and private homes, were used as low-risk areas. In addition, to better understand the distribution of Legionella and the bacterial community in the air samples collected from outdoor and indoor environments, 16S rRNA gene amplicon sequencing was performed.

\section{Results}

\section{Recovery of Legionella from spiked samples}

In this study, the detection limit of the GPCR method was 10 Legionella colony-forming units (CFU) equivalents in $1 \mathrm{~m}^{3}$ of air, and the detection limits both of the amoebic co-culture and the plate culture methods were $10^{4} \mathrm{CFU} / \mathrm{m}^{3}$, as determined using Legionella-spiked samples.

\section{Prevalence of Legionella species in air samples Amoebic co-culture}

Of the 202 collected air samples, 150 (129 from roads and 21 from bathrooms) were tested by amoebic coculture (Supplementary Table S1). Legionella species were not isolated by amoebic co-culture from any of the 150 air samples. Although 20 Legionella-suspected colonies grew on glycine-vancomycin-polymyxin Bcycloheximide (GVPC) agar plates, they also grew on blood agar plates, indicating that they do not belong to the genus Legionella. However, 10-fold more Legionella DNA was observed in 10 samples $(10 / 150,6.7 \%)$ using qPCR after amoebic co-culture than in identical samples analyzed without co-culture (Supplementary Table S1). PCR amplification of the macrophage infectivity potentiator (mip) gene was performed in these samples, and a PCR product was obtained from only one sample collected from a bathroom (Legionella-specific 16S rRNA genes, $1.45 \log _{10}$ copies $/ \mathrm{m}^{3}$ ) in which the amount of $L e$ gionella DNA was increased by $5.8 \times 10^{4}$-fold after amoebic co-culture $\left(6.21 \log _{10}\right.$ copies $\left./ \mathrm{m}^{3}\right)$. Direct 
sequencing of the PCR product showed that the mip gene sequence in the sample had $92 \%$ identity with the mip gene of L. nautarum using BLAST.

\section{qPCR}

Legionella DNA was detected in 114/151 (75.5\%) air samples collected near roads and at all 12 sampling sites (locations A-L, Supplementary Table S1). Legionella DNA was also detected in 15/21 (71.4\%) air samples collected from $14 / 17$ bath facilities and 11/30 (36.7\%) samples collected from $4 / 4$ other indoor sites. The positivity rates for samples collected near roads and from bathrooms were significantly higher than those for samples collected from indoor sites other than bathrooms $(P<0.05$; Fisher's exact test followed by post hoc Holm test). The geometric means \pm standard deviation (SD) $\left(\log _{10}\right.$ copies $\left./ \mathrm{m}^{3}\right)$ of Legionella-specific 16S rRNA gene in the Legionella DNA-positive samples were $1.80 \pm 0.52,1.82 \pm 0.50$, and $0.88 \pm 0.56$ for roads $(\mathrm{N}=114)$, bathrooms $(\mathrm{N}=15)$, and other indoor sites $(\mathrm{N}=11)$, respectively. The values for these three sampling source types were determined to be significantly different by one-way analysis of variance (one-way ANOVA) $(P<0.05)$. Moreover, the TukeyKramer method revealed that the amount of Legionella DNA was significantly different between the samples from roads and those collected in indoor sites other than bathrooms $(P<0.05)$ (Table 1$)$.

\section{Geographic characterization of air samples collected from roads}

At the 12 sampling sites near asphalt roads (locations A-L, $\mathrm{N}=151$ ), the detection rates of Legionella DNA ranged from 60.0 to $93.3 \%$ (Supplementary Table S2). The geometric means \pm SD $\left(\log _{10}\right.$ copies $\left./ \mathrm{m}^{3}\right)$ of Legionella-specific $16 \mathrm{~S}$ rRNA genes in the Legionella DNApositive samples ranged from $1.54 \pm 0.66$ to $2.03 \pm 0.42$. The differences in the detection rates according to sampling site and the amount of Legionella-specific $16 \mathrm{~S}$ rRNA genes according to sampling site were not significant by Fisher's exact test followed by post hoc Holm test and one-way ANOVA, respectively $(P \geq 0.05)$.

\section{Meteorological characterizations of air samples collected from roads}

We assessed the correlation between the climatic conditions (air temperature, relative humidity, total precipitation, and wind speed) and the amount of Legionellaspecific $16 \mathrm{~S}$ rRNA genes $\left(\log _{10}\right.$ copies $\left./ \mathrm{m}^{3}\right)$ in the Legionella DNA-positive samples (Table 2). The amount of Legionella DNA was correlated with the monthly total precipitation $(\mathrm{N}=17, r=0.56, P<0.01)$. It was also directly and inversely correlated with the daily total precipitation for seven days $(\mathrm{N}=114, r=0.21, P=0.01)$ and one day $(\mathrm{N}=114, r=-0.29, P<0.01)$ before the sampling day, respectively. The scatter plots of total precipitation and the amount of Legionella DNA are shown in Fig. 1. The detection rate and the geometric mean of $\mathrm{Le}$ gionella DNA seven days before the sampling day at a daily total precipitation of $>10 \mathrm{~mm}(100 \%, 16 / 16 \mathrm{sam}$ ples; $2.07 \pm 0.32 \quad \log _{10}$ copies $\left./ \mathrm{m}^{3}, \quad \mathrm{~N}=16\right)$ were also higher than those at a daily total precipitation of $\leq 10$ $\mathrm{mm}\left(72.6 \%, 98 / 135\right.$ samples; $1.75 \pm 0.53 \log _{10}$ copies $/ \mathrm{m}^{3}$, $\mathrm{N}=98)(P<0.05$; Fisher's exact test and Student's $t$-test, respectively). However, the geometric mean of Legionella DNA one day before the sampling day at a daily total precipitation of $\leq 10 \mathrm{~mm}\left(1.83 \pm 0.49 \log _{10}\right.$ copies $/ \mathrm{m}^{3}$, $\mathrm{N}=99$ ) was higher than that at a daily total precipitation of $>10 \mathrm{~mm}\left(1.55 \pm 0.64 \log _{10}\right.$ copies $/ \mathrm{m}^{3}, \mathrm{~N}=15 ; P<$ 0.05 , Student's $t$-test); the detection rates of Legionella DNA one day before the sampling day at daily total precipitation of $\leq 10 \mathrm{~mm}$ (75.0\%, 99/132 samples) and $>10$ $\mathrm{mm}(78.9 \%, 15 / 19$ samples) were not significantly different $(P \geq 0.05$, Fisher's exact test).

\section{S rRNA gene amplicon sequencing Sequencing analysis}

$16 \mathrm{~S}$ rRNA gene amplicon sequencing was performed on randomly selected samples collected from roads $(\mathrm{N}=30)$ and all samples collected from bathrooms $(\mathrm{N}=21)$ and other indoor sites $(\mathrm{N}=30)$. The median number of reads after quality filtering, denoising, merging, and removing chimeric sequences was 62,246 (range, 9,852-246,625) from roads, 112,471 (range, 16,534-341,587) from bathrooms, and 111,835 (range, 16,009-250,862) from other indoor sites. A total of $8,174,054$ reads $(100,914$ reads

Table 1 Prevalence of Legionella species in air samples

\begin{tabular}{llll}
\hline Sampling site & No. of samples & $\begin{array}{l}\text { No. (\%) of Legionella-positive } \\
\text { samples by qPCR }\end{array}$ & $\begin{array}{l}\text { Geometric mean } \pm \text { SD (log } \text { (no Copies/m }^{\mathbf{3}} \text { ) } \\
\text { in Legionella DNA-positive samples }\end{array}$ \\
\hline Road & 151 & $114(75.5) \mathrm{A}$ & $1.80 \pm 0.52 \mathrm{C}$ \\
Bathroom & 21 & $15(71.4) \mathrm{A}$ & $1.82 \pm 0.50 \mathrm{CD}$ \\
Indoor site & 30 & $11(36.7) \mathrm{B}$ & $0.88 \pm 0.56 \mathrm{D}$ \\
\hline
\end{tabular}

${ }^{a}$ Values with different letters are significantly different $(P<0.05)$. Data were analyzed by Fisher's exact test followed by post hoc Holm test.

${ }^{b}$ Values with different letters are significantly different $(P<0.05)$. Data were analyzed by one-way ANOVA followed by Tukey-Kramer post-hoc test for multiple comparisons. 
Table 2 Correlation between the climatic conditions and the amount of Legionella DNA ${ }^{a}$

\begin{tabular}{|c|c|c|c|c|c|c|c|c|}
\hline & \multicolumn{2}{|c|}{$\begin{array}{l}\text { Air temperature } \\
\left(\text { mean, }{ }^{\circ} \mathrm{C}\right)\end{array}$} & \multicolumn{2}{|c|}{$\begin{array}{l}\text { Relative humidity } \\
\text { (mean, \%) }\end{array}$} & \multicolumn{2}{|c|}{$\begin{array}{l}\text { Total precipitation } \\
(\mathrm{mm})\end{array}$} & \multicolumn{2}{|c|}{$\begin{array}{l}\text { Wind speed } \\
\text { (mean, m/s) }\end{array}$} \\
\hline & $r$ & $P$ & $r$ & $P$ & $r$ & $P$ & $r$ & $P$ \\
\hline \multicolumn{9}{|l|}{ Daily value $(\mathrm{N}=114)$ : } \\
\hline on the sampling day (lag day 0 ) & -0.10 & 0.22 & 0.13 & 0.11 & 0.17 & $0.04^{c}$ & -0.10 & 0.22 \\
\hline one day before the sampling day (lag day 1 ) & 0.01 & 0.90 & -0.19 & $0.02^{c}$ & $-0.29^{b}$ & $<0.01^{\mathrm{c}}$ & 0.16 & $0.049^{c}$ \\
\hline two days before the sampling day (lag day 2) & -0.07 & 0.39 & -0.15 & 0.06 & 0.12 & 0.16 & 0.08 & 0.34 \\
\hline three days before the sampling day (lag day 3 ) & -0.10 & 0.24 & -0.01 & 0.90 & -0.11 & 0.17 & -0.15 & 0.06 \\
\hline four days before the sampling day (lag day 4) & -0.06 & 0.48 & 0.03 & 0.74 & 0.02 & 0.85 & -0.19 & $0.02^{c}$ \\
\hline five days before the sampling day (lag day 5) & -0.09 & 0.29 & -0.05 & 0.53 & -0.06 & 0.45 & -0.08 & 0.35 \\
\hline six days before the sampling day (lag day 6) & -0.11 & 0.17 & 0.04 & 0.65 & -0.09 & 0.28 & 0.07 & 0.39 \\
\hline seven days before the sampling day (lag day 7) & -0.13 & 0.12 & 0.14 & 0.09 & $0.21^{b}$ & $0.01^{c}$ & -0.07 & 0.37 \\
\hline Monthly value $(N=17)$ & -0.08 & 0.35 & 0.08 & 0.34 & $0.56^{\mathrm{b}}$ & $<0.01^{c}$ & -0.04 & 0.63 \\
\hline
\end{tabular}

${ }^{a}$ Geometric mean $\left(\log _{10}\right.$ copies $\left./ \mathrm{m}^{3}\right)$ of Legionella-specific $16 \mathrm{~S}$ rRNA genes in the Legionella DNA-positive samples.

${ }^{\mathrm{b}}$ An absolute Pearson's $r$ value $\geq 0.20$ was considered to be correlated.

${ }^{c} P<0.05$ was considered significant.

per sample) were assigned to 18,426 amplicon sequence variants (ASVs).

\section{Legionella-assigned reads}

Reads from Legionella species were detected in 15/81 samples (19\%) in total: $9 / 30$ samples (30\%) collected near roads (mean proportion of reads, $0.11 \%$ ), 5/21 samples $(24 \%)$ collected in bathrooms (mean, $0.04 \%$ ), and $1 /$ 30 samples $(3 \%)$ collected from indoor sites other than bathrooms (mean, $0.03 \%$ ). The rate of positivity for samples collected near roads was significantly higher than that for samples collected from indoor sites other than bathrooms $(P<0.05$; Fisher's exact test followed by post hoc Holm test).
Among the 15 samples in which Legionella reads were detected, Legionella species was identified in 6 samples (Table 3). At the species level, L. pneumophila was identified in $2 / 30$ samples collected near roads (sample no. 22 and 86; the proportion of reads, 0.09 and $0.11 \%$ of the total reads number in each positive sample) and in $1 / 21$ samples collected in bathrooms (sample no. 98; $0.15 \%)$. L. birminghamensis was identified in $1 / 30$ samples collected from roads (sample no. 107, 0.81\%). L. geestiana was identified in 1/30 samples collected from roads (sample no. $35,0.02 \%$ ). L. nautarum was identified in 1/30 samples collected from indoor sites other than bathrooms (sample no. 159, 0.79\%). The reads in the remaining 9 Legionella-positive samples could not be identified at the species level.

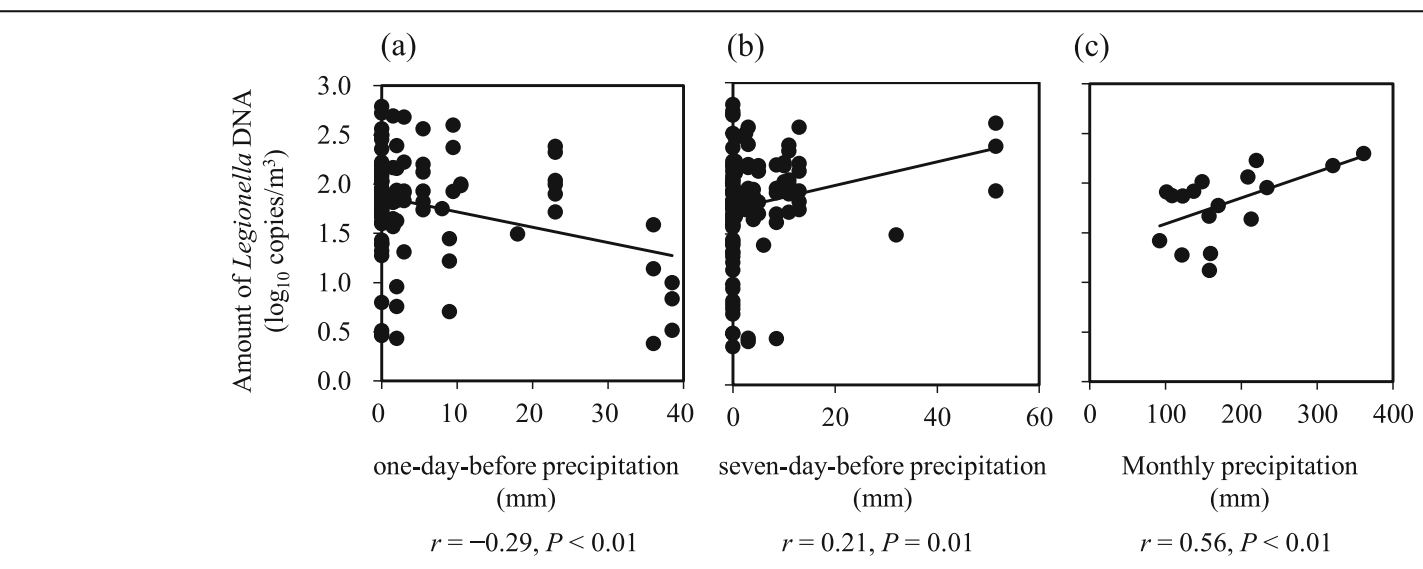

Fig. 1 Scatter plots of total precipitation and the amount of Legionella DNA. Total precipitation $(\mathrm{mm})$ at each sampling time point and the amount of Legionella-specific $16 \mathrm{~S}$ rRNA gene $\left(\log _{10}\right.$ copies $\left./ \mathrm{m}^{3}\right)$ in the Legionella DNA-positive air samples collected near roads in Toyama Prefecture, Japan. (a) Daily precipitation one day before sampling (lag day 1). (b) Daily precipitation seven days before sampling (lag day 7). (c) Monthly precipitation 


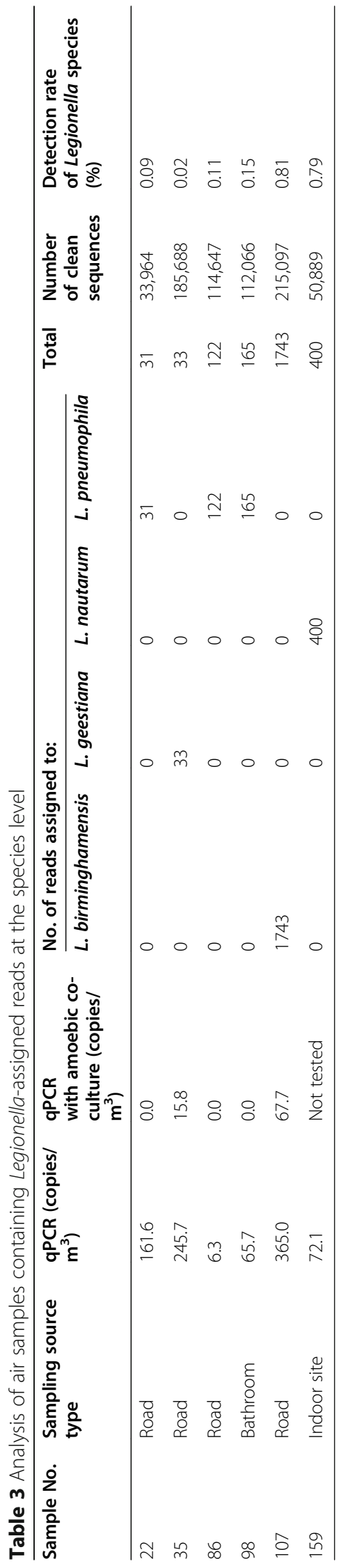




\section{Characteristics of the bacterial communities}

At the genus level, 485, 421, and 368 bacterial genera were detected in samples collected from roads, bathrooms, and other indoor sites, respectively (Supplementary Figure S1). The top three most abundant bacterial genera were Sphingomonas (21.1\%), Streptococcus (14.6\%), and Methylobacterium (1.6\%) in the samples collected near roads; Sphingomonas (17.6\%), Pseudomonas (5.4\%), and Methylococcus (4.3\%) in the samples collected in bathrooms, and Sphingomonas (19.2\%), Achromobacter (5.0\%), and Arthrobacter (3.8\%) in the samples collected from indoor sites other than bathrooms.

The alpha diversity index based on Faith's phylogenetic diversity, a qualitative measure of bacterial community richness that incorporates phylogenetic relationships between features, in air samples from roads were much higher value than those from other indoor sites $[Q<0.05$; Kruskal-Wallis test with BenjaminiHochberg false discovery rate (FDR) correction] (Supplementary Figure S2). Beta diversity analysis showed that a portion of the air samples collected from roads and indoor sites other than bathrooms were separate from samples collected from bathrooms (Supplementary Figure S3). Linear discriminant analysis (LDA) effect size (LEfSe) analysis to determine the significantly different taxa among the three sampling sources revealed 15 genera with LDA scores of at least 3.0 (Fig. 2; $P<0.05$, pairwise Wilcoxon test). Specifically, we found that the following four genera were enriched in the samples (LDA score > 4.0): Pseudomonas, Vibrio, and Staphylococcus in samples from bathrooms (shown in red), and Achromobacter in samples from other indoor sites (shown in green).

\section{Discussion}

We demonstrated that DNA from Legionella species was widely present in aerosols derived from outdoor sites near asphalt roads, especially during the rainy season, regardless of sampling site. Legionella DNA was detected in more than $70 \%$ of the air samples collected near roads. The positivity rate for samples collected near roads was almost the same as that for samples collected in the bathrooms of public bath facilities, which are a major source of legionellosis in Japan and was significantly higher than that for samples collected from other indoor sites $(P<0.05)$. Similarly, Montagna et al. reported that Legionella DNA was detected in $72.7 \%$ (8/ 11) of air samples collected from bathrooms in healthcare facilities using a Coriolis $\mu$ air sampler by qPCR [14]. Low-level detection of Legionella DNA in air samples collected from other indoor sites (buildings and private homes) may be because airborne bacteria from the outdoor environment enter buildings and houses via ventilation components such as air-conditioning systems [20]. Although the sampling height in this study was not at $150-180 \mathrm{~cm}$ above ground level, which is the average height of an adult, owing to the stability of the air

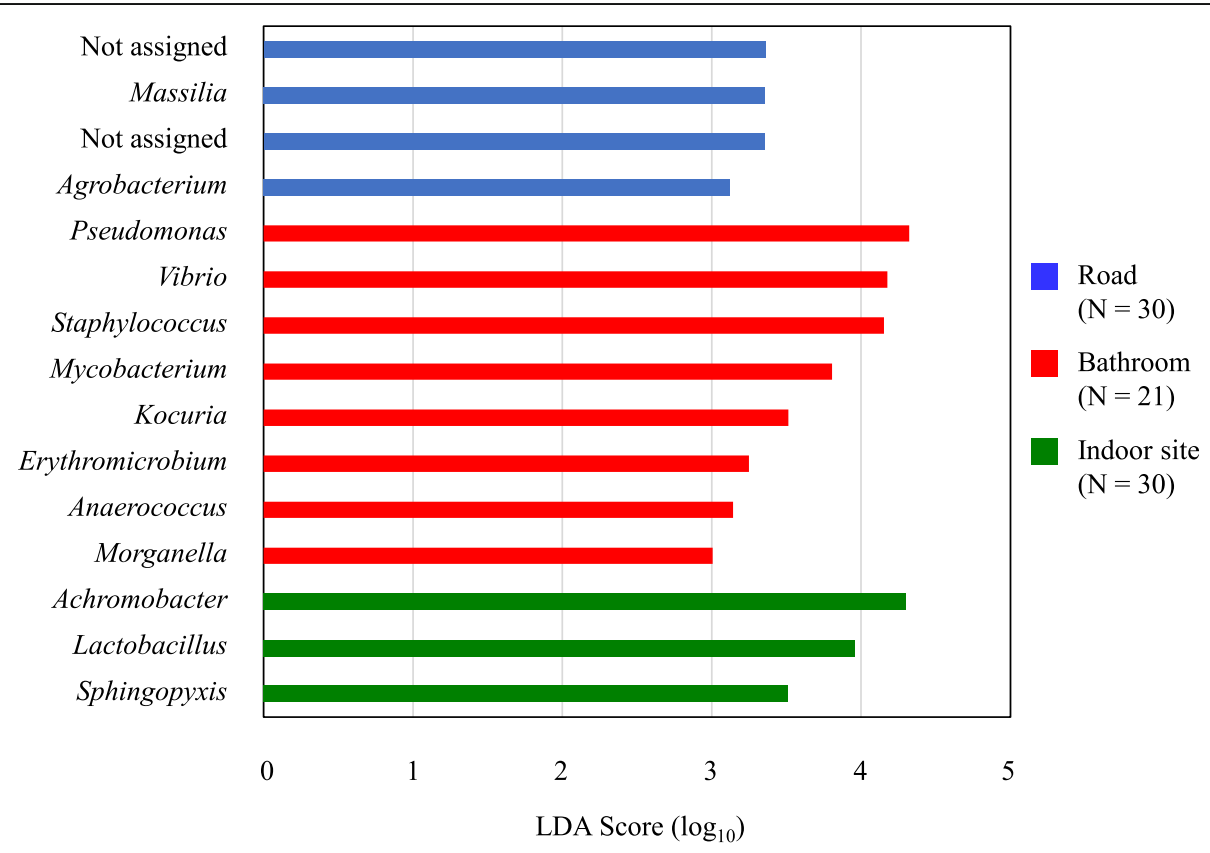

Fig. 2 LEfSe analysis. LEfSe identified the most differentially abundant genera among the road (blue bar), bathroom (red bar), and other indoor sites (green bar). A total of 15 bacterial genera were considered significant. The threshold for the logarithmic LDA score is 3.0, with a $P$ value less than 0.05 (pairwise Wilcoxon test) 
sampler, our results showed the existence of aerosols containing Legionella species near asphalt roads. Further investigation of the relationship between sampling height and the prevalence of Legionella species in aerosols is needed to reveal the risk of inhalation of aerosols containing Legionella species.

No Legionella species were isolated from any of the collected air samples (roads, bathrooms, and other indoor sites) by amoebic co-culture. The discrepant results for the amoebic co-culture and qPCR methods may be due to the detection limit of each method. Although our control experiment showed that the detection limit of the amoebic co-culture method was comparable to those of the plate culture method, Conza et al. reported that the detection limit of the amoebic co-culture method was 3 logs high sensitive than those of the plate culture method and that viable Legionella cells were isolated by amoebic co-culture from aerosols collected at composting facilities [15, 18]. Edagawa et al. reported that a combination of amoebic co-culture and qPCR might be useful to detect viable Legionella cells [21]. In this study, 10 -fold more Legionella DNA was observed in 10 samples after amoebic co-culture, indicating that amoebic co-culture promoted the growth of Legionella cells such as VBNC state in the environment. The recovery of Legionella from air sample may be due to the state of Legionella cells. In addition, it is also possible Legionella species may not have been isolated because of the stress encountered during aerosolization and the air sampling process, which may have led to a loss of culturability [22]. In fact, Montagna et al. reported that viable Legionella cells in air samples collected using a Coriolis $\mu$ air sampler could not be isolated by culture [14]. Improvements in the amoebic co-culture method, such as the strains of amoeba used for co-culture and the incubation periods with the amoeba, may also allow the isolation of Legionella from aerosols. Nonetheless, new sampling and/or culture methods need to be established to allow the isolation of Legionella species from aerosols.

It seems plausible that precipitation is positively associated with the occurrence of legionellosis [23]. Our study also showed a positive correlation between the monthly total precipitation and the amount of Legionella DNA present in aerosols collected near roads. According to previous studies, the number of legionellosis cases in Japan peak in July, which is in the second half of the rainy season [24, 25]. Thus, there is a risk of contracting legionellosis near asphalt roads, especially during the rainy season. The amount of Legionella DNA was also directly and inversely correlated with the daily total precipitation of seven days and one day before sampling, respectively. Our results suggest that Legionella may have multiplied within amoeba present in the environment after precipitation at the seven-day-before sampling time point, whereas the dry condition during the day before the sampling time point may have favored the release of aerosols of small particle sizes from the ground into the atmosphere because of splashing or the effect of wind. Alternatively, the survival rate of Legionella in aerosols may be different due to climatic conditions.

We assessed the distribution of Legionella and the bacterial community in air samples using $16 \mathrm{~S}$ rRNA gene amplicon sequencing. Reads from Legionella species were detected in $30 \%$ of the air samples collected near roads, which was similar to the proportion of reads detected in bathrooms and was significantly higher than those detected in other indoor sites. L. pneumophila, a major causative agent of Legionnaires' disease [26], was also detected in aerosols collected near roads and in bathrooms. In outdoor environment, other non-L. pneumophila species, such as L. longbeachae, derived from soil were also important for legionellosis [27], indicating the importance of the detection of non-L. pneumophila and species identification. Our results suggest that legionellosis may be acquired by inhaling aerosols from areas near asphalt roads, as well as in bathrooms. The detection rate of Legionella reads by $16 \mathrm{~S}$ rRNA gene amplicon sequencing was lower than that by qPCR (75.5\%). This may be due to the PCR amplification bias of the 16S rRNA gene. Conversely, the detection rate and geometric mean of Legionella DNA by qPCR for samples in which Legionella reads were detected using $16 \mathrm{~S}$ rRNA gene amplicon sequencing (93.3\%, 14/15 samples; $2.04 \pm 0.56, \quad \log _{10}$ copies $/ \mathrm{m}^{3}$ ) were significantly higher than those in the samples in which Legionella reads were not detected by $16 \mathrm{~S}$ rRNA gene amplicon sequencing $\left(57.6 \%, 38 / 66\right.$ samples; $1.49 \pm 0.56 \log _{10}$ copies $\left./ \mathrm{m}^{3}\right)(P<0.05$; Fisher's exact test and Student's $t$-test, respectively). Thus, the qPCR results for Legionella DNA were correlated with the $16 \mathrm{~S}$ rRNA gene amplicon sequencing results.

Our study revealed that the bacterial diversity in outdoor environment was comparable to that in indoor environment which contains aerosol-generating features and higher than that in indoor environment without the features. In addition, the bacterial community composition differed in air samples from outdoor and indoor environments. Then, we analyzed what genera account for the diversity and significance by LEfSe analysis. Sphingomonas was the most frequently detected genus in the air samples. This genus has been found in various environments, such as soil, water, clinical specimens, air, and other locations [28-30], indicating the opportunity for these bacteria to be released into the air. Pseudomonas and Achromobacter were significantly enriched in air samples from bathrooms and other indoor sites, respectively. These genera have frequently been detected in bathwater and moist indoor environments [31, 32]. 
Thus, our results agreed with those reported in other studies. These findings provide a foundation for understanding the health effects of aerosols in these environments.

In this study, there are several limitations. First, it has not been investigated whether DNA from Legionella species detected in air samples is derived from VBNC or dead cells. Although various stress factors may induce Legionella cells to enter a VBNC state, these cells can still directly infect human macrophages and amoebae, indicating that VBNC Legionella cells can cause disease in humans $[33,34]$. Several studies have shown that VBNC Legionella in water samples regain culturability in amoebic co-culture [17, 35]. Although Legionella is sensitive to environmental stresses such as desiccation and UV irradiation, amoeba cysts, which are resistant amoebal forms that can survive under stress conditions [36], may play a role in the survival and transmission of airborne Legionella. Further investigations using techniques such as ethidium monoazide with qPCR, which can selectively quantify viable Legionella cells because ethidium monoazide prevents the amplification of DNA from membrane-damaged dead cells [37], are needed to obtain a detailed understanding of the state of Legionella in aerosols. Second, regarding the outdoor sites near asphalt roads, information on the sampling sites such as traffic volume at the sampling time and the precise number of people walking on foot on the neighboring was missing. A risk of contracting legionellosis depends not only on the concentration of Legionella in aerosols, but also on the exposure to Legionella cells. However, the exposure assessment was not investigated in this study. Furthermore, we could investigated only 12 sampling sites. Thus, it remains unclear how the road conditions influenced aerosolization of water. The relevance on the road conditions and Legionella prevalence in aerosols seems an interesting topic for future research.

\section{Conclusions}

Here, we demonstrated that DNA from Legionella species was widely present in aerosols collected from outdoor sites near asphalt roads, especially during the rainy season, regardless of the sampling site. Our findings suggest that there may be a risk of exposure to Legionella species not only in bathrooms but also in the areas surrounding asphalt roads. Therefore, the possibility of contracting legionellosis in daily life should be considered. Further studies are needed to evaluate the risk of legionellosis and develop prevention strategies.

\section{Methods}

\section{Air samples}

We investigated outdoor sites near asphalt roads, indoor sites in bathrooms next to bathtubs in public bath facilities, and other indoor sites in Toyama Prefecture, Japan (Supplementary Table S1). A total of 202 air samples were collected, including 151 samples from 12 outdoor sites (locations A-L) near asphalt roads, on various days in sunny, cloudy, and rainy weather for almost 1 year from June 2016 to April 2017. The numbers of air samples collected near roads at the 12 sampling sites were as follows: $\mathrm{A}, \mathrm{N}=15 ; \mathrm{B}, \mathrm{N}=12 ; \mathrm{C}, \mathrm{N}=12 ; \mathrm{D}, \mathrm{N}=$ 11; $\mathrm{E}, \mathrm{N}=10 ; \mathrm{F}, \mathrm{N}=13 ; \mathrm{G}, \mathrm{N}=11 ; \mathrm{H}, \mathrm{N}=11 ; \mathrm{I}, \mathrm{N}=17$; J, $\mathrm{N}=13 ; \mathrm{K}, \mathrm{N}=11$; and $\mathrm{L}, \mathrm{N}=15$. Traffic volume (vehicles/24 h) was shown in Supplementary Table S2 [38]. Although it was not the data at the time of air sampling, we used them as the latest published data (2015) for reference. These sampling sites were located near the external city roads, and there were several people walking on foot on the neighboring roads during the sampling period.

Twenty-one samples were collected from bathrooms next to bathtubs in 17 public bath facilities from October 2016 to February 2017 (16 were collected while operating aerosol-generating devices in a bathtub, such as jet circulation with or without air induction bubbles). The remaining 30 samples were collected in rooms and corridors from two buildings and two private houses from March 2017 to February 2018 (indoor sites other than bathrooms). At the sites, devices that generate aerosols of water, such as showers and taps, were not operated during the sampling period.

\section{Sample collection}

For each sampling, a portable cyclone-based air sampler (Coriolis $\mu$; Bertin Technologies, France) was placed approximately $70 \mathrm{~cm}$ from the ground. The air samples were collected in $15 \mathrm{~mL}$ of a solution containing $0.005 \%$ Tween 80 at a flow rate of $300 \mathrm{~L} / \mathrm{min}$ for $10 \mathrm{~min}$. Depending on the climatic conditions, the remaining volume after sampling was 6-14 $\mathrm{mL}$, and each sample solution was vortexed for $1 \mathrm{~min}$.

\section{Control experiment}

We assessed the detection limits of the culture, amoebic co-culture, and qPCR methods from the air samples as described previously with a slight modification [18]. In this study, air samples were collected in the field with a Coriolis $\mu$ under the conditions described above. For our experiments, we used $15 \mathrm{~mL}$ of sterilized $0.005 \%$ Tween 80 solution spiked with known amounts of Legionella. Five $14.7 \mathrm{~mL}$ aliquots of sterilized $0.005 \%$ Tween 80 were spiked with $0.3 \mathrm{~mL}$ of serial dilutions of L. pneumophila (ATCC33152) to obtain suspensions containing 3$30,000 \mathrm{CFU}$ in $15 \mathrm{~mL}$ of $0.005 \%$ Tween 80 . Then, a collector cone was filled with the spiked solution and connected to the Coriolis $\mu$. After operating the Coriolis $\mu$ at a flow rate of $300 \mathrm{~L} / \mathrm{min}$ for $10 \mathrm{~min}$ in a pre- 
cleaned biological safety cabinet, the spiked solution was used for culture, amoebic co-culture, and qPCR. Fifteen milliliters of sterile $0.005 \%$ Tween 80 solution was used as a negative control. All measurements were performed in duplicate.

\section{qPCR}

For qPCR, DNA was extracted from a $2 \mathrm{~mL}$ aliquot of sample solution. The suspension was centrifuged at 20,000 $\times g$ at room temperature for $5 \mathrm{~min}$ and then resuspended in $100 \mu \mathrm{L}$ of $5 \%(\mathrm{w} / \mathrm{v})$ Chelex-100 solution ([39]; Bio-Rad Laboratories, CA, USA). The suspension was boiled for $10 \mathrm{~min}$ and then centrifuged at 20,000 $\times \mathrm{g}$ for $5 \mathrm{~min}$ at room temperature. The supernatant was used as the DNA template, and qPCR was carried out using the CycleavePCR Legionella (16S rRNA) Detection Kit (Takara Bio, Shiga, Japan) and a Thermal Cycler Dice Real Time System II (Takara Bio). According to the manufacturer's instructions, this qPCR assay was positive for 74 Legionella strains (48 Legionella species) and negative for 14 non-Legionella strains (11 non-Legionella species: Shigella sonnei, Escherichia coli, Vibrio parahaemolyticus, Campylobacter jejuni, Salmonella enterica, Clostridium botulinum, Clostridium perfringens, Staphylococcus aureus, Yersinia enterocolitica, Listeria monocytogenes, and Bacillus cereus), and 1 CFU of L. pneumophila corresponded to 23 copies of $16 \mathrm{~S}$ rRNA genes, which was calculated from DNA standard curve.

\section{Isolation of Legionella species}

Amoebic co-culture was performed as described previously [40]. Acanthamoeba species isolated from cooling tower water were incubated in proteose peptone-yeast extract-glucose-cysteine medium at $30^{\circ} \mathrm{C}$ for $5^{-7}$ days. Cells were washed and resuspended in phosphatebuffered saline, and then $0.5 \mathrm{~mL}$ of the suspension (approximately $1.0 \times 10^{5}$ cells) was added to the remaining amount of the sampling solution (4-12 mL) after qPCR sampling $(2 \mathrm{~mL})$. To prevent evaporation, the samples were incubated at $35^{\circ} \mathrm{C}$ in $50 \mathrm{~mL}$ screw-cap tubes. After 4 weeks, the sample was mixed with equal volumes of $0.2 \mathrm{~mol} / \mathrm{L} \mathrm{KCl}-\mathrm{HCl}$ buffer $(\mathrm{pH} 2.2)$ for $15 \mathrm{~min}$ at room temperature, and $0.2 \mathrm{~mL}$ was spread on a GVPC agar plate (Nissui Pharmaceutical Co., Tokyo, Japan). The agar plates were incubated at $35{ }^{\circ} \mathrm{C}$ for 7 days in a humidified chamber. Candidate colonies that were smooth gray with characteristic outward structures of Legionella, i.e., cutglass-like or mosaic-like in appearance were viewed under a stereomicroscope with oblique illumination [41] and were subcultured on a buffered charcoal-yeast extract (BCYE) agar plate with L-cysteine (bioMérieux, Lyon, France) and a blood agar plate (Eiken Chemical, Tokyo, Japan). Colonies growing only on the BCYE agar plate and not on the blood agar plate were presumed to belong to the genus Legionella.

\section{Sequencing of the mip gene}

For samples in which the amount of Legionella DNA increased after amoebic co-culture, the species of $L e$ gionella was determined. DNA was extracted from a $2 \mathrm{~mL}$ sample of the amoebic co-culture using Chelex100 solution as described above. The mip gene was directly amplified and sequenced as previously described [42].

\section{Next-generation sequencing for 16S rRNA gene amplicon}

DNA samples extracted with Chelex-100 solution were used for next-generation sequencing. For air samples randomly selected from roads $(\mathrm{N}=30)$ and collected from bathrooms $(\mathrm{N}=21)$ and other indoor sites $(\mathrm{N}=30)$, the bacterial $16 \mathrm{~S} \mathrm{~V} 3-4$ region was amplified using Tks Gflex DNA Polymerase (Takara Bio) with the primers 341F (5'-TCGTCGGCAG CGTCAGATGTGTATAAGAGACAG-3') and 806R (5'-GTCTCGTGGGCTCGGAGATGTGTATAAGAG ACAG-3'). A $16 S$ rRNA gene amplicon library was prepared according to the $16 \mathrm{~S}$ Metagenomic Sequencing Library Preparation protocol for Illumina MiSeq (Illumina, San Diego, CA, USA) and then sequenced using an Illumina MiSeq instrument with the MiSeq Reagent Kit v3 (600 cycles).

\section{Bioinformatic processing}

Microbiome bioinformatics was performed using QIIM E2 version 2019.7 [43]. Imported demultiplexed sequence data were denoised using DADA2 [44] (via q2dada2). All ASVs were aligned with mafft [45] (via q2alignment), which was used to construct a phylogeny with fasttree2 [46] (via q2-phylogeny). Taxonomy, from kingdom to species, was assigned to ASVs using the q2feature-classifier [47] based on the classify-sklearn naïve Bayes taxonomy classifier against the GreenGenes 13_8 $99 \%$ OTU database [48]. However, the short fragments generated by $16 \mathrm{~S}$ rRNA amplicon sequencing $(<500 \mathrm{bp}$ in this study) limit their use for $16 \mathrm{~S}$ rRNA gene-based bacterial identification at the species level due to the sequence similarity of the variable regions [49]. Alpha (Faith's phylogenetic diversity [50]) and beta diversity metrics (weighted UniFrac [51]) were performed to assess the diversity of the microbial communities in the air samples. These metrics were estimated using q2diversity after samples were rarefied (subsampled without replacement) to 9,852 sequences per sample. The coordinate points of beta diversity were shown in Supplementary Table S3. Different taxa with significant differences between sampling source types were assessed using the LEfSe program with the following parameters (alpha value for pairwise Wilcoxon test set at 0.05 ; the logarithmic LDA score threshold was set at 3.0) using 
the Galaxy Hutlab online platform [52] (https:// huttenhower.sph.harvard.edu/galaxy/).

\section{Statistical analysis}

To investigate the relationships between the rate of Legionella DNA detection and sampling source type and between the detection rate and sampling site (locations A-L), Fisher's exact test followed by post hoc Holm test were performed. Fisher's exact test was also used to compare the rates of Legionella DNA detection in samples according to total precipitation (high and low). We also investigated the relationships between the amount of Legionella DNA and sampling source type and between the amount of Legionella DNA and sampling site (locations A-L) using oneway ANOVA followed by Tukey-Kramer multiple comparisons. Student's t-test was performed to compare the amount of Legionella DNA between samples with high and low total precipitation. These tests were performed using the $\mathrm{R}$ statistical software package (version 3.0.0). Pearson's correlation coefficient $(r)$ between climatic conditions (air temperature, relative humidity, total precipitation, and wind speed) and the amount of Legionella DNA was calculated using Excel (Microsoft, Redmond, WA, USA). An absolute Pearson's $r$ value $\geq 0.20$ was considered indicative of a correlation, and a $P$ value less than 0.05 was considered significant. The Kruskal-Wallis test with BenjaminiHochberg FDR correction ( $Q$ value [53]) was performed to compare alpha diversity indices using QIIME2. The $Q$ value cutoff was set to 0.05 .

\section{Meteorological data collection}

During the study period (2016-2018), meteorological data were obtained from two main weather stations in Fushiki and Toyama, Toyama Prefecture, Japan [54]. The meteorological data used in this study were monthly or daily values of air temperature $\left(\right.$ mean, $\left.{ }^{\circ} \mathrm{C}\right)$, relative humidity (mean, \%), total precipitation $(\mathrm{mm})$, and wind speed (mean, $\mathrm{m} / \mathrm{s}$ ). To consider the period for Legionella growth in the environment, the amount of Legionella DNA $\left(\log _{10}\right.$ copies $\left./ \mathrm{m}^{3}\right)$ and the daily meteorological values for lag day- 0 to 7 were compared. To analyze seasonal trends, the amount of Legionella DNA $\left(\log _{10}\right.$ copies $/ \mathrm{m}^{3}$ ) and monthly values were compared (Supplementary Table S4).

\footnotetext{
Abbreviations

qPCR: Quantitative PCR; GVPC: Glycine-vancomycin-polymyxin Bcycloheximide; CFU: Colony-forming units; SD: Standard deviation; ANOVA: Analysis of variance; mip: Macrophage infectivity potentiator; VBNC: Viable but non-culturable; ASV: Amplicon sequence variants; LDA: Linear discriminant analysis; LEfSe: Linear discriminant analysis effect size; BCYE: Buffered charcoal-yeast extract; FDR: False discovery rate
}

\section{Supplementary Information}

The online version contains supplementary material available at https://doi. org/10.1186/s12866-021-02275-2.

\section{Additional file 1.}

Additional file 2 .

\section{Acknowledgements}

We thank Editage for the English language review. A portion of the results of this study was presented as an oral communication at the 6th meeting of the ESGLI Study Group for Legionella Infections Conference, Athens, Greece, September 10-12, 2019.

\section{Authors' contributions}

JK carried out the experiments, performed the bioinformatics and statistical analysis, and was a major contributor in writing the manuscript. MW, KK, TK, and $\mathrm{KU}$ participated in the analysis. FK, JA-M, and $J$ participated in writing the manuscript. All authors read and approved the final manuscript.

\section{Funding}

This work was supported by Health and Labor Sciences research grants (grant numbers H28-Shinko-Ippan-006 and 19LA1006 to J.A.-M) and JSPS KAKENHI (grant number 20K18922). The funding bodies had no role in the design of the study and collection, analysis, interpretation of data and in writing the manuscript.

\section{Availability of data and materials}

The datasets supporting the conclusions of this article are deposited in the DNA Data Bank of Japan (http://www.ddbj.nig.ac.jp/) under accession numbers LC472487 (http://getentry.ddbj.nig.ac.jp/getentry/na/LC472487/

?format=flatfile\&filetype $=$ html\&trace $=$ true\&show_suppressed $=$ false\&limit $=10$ ) for the mip gene and DRA008310 (https://ddbj.nig.ac.jp/DRASearch/ submission?acc=DRA008310) and DRA009422 (https://ddbj.nig.ac.jp/ DRASearch/submission?acc=DRA009422) for the 16 S rRNA gene amplicons. The data deposited is publicly available.

\section{Declarations}

Ethics approval and consent to participate Not applicable.

Consent for publication

Not applicable.

\section{Competing interests}

The authors declare that they have no competing interests.

\section{Author details}

${ }^{1}$ Department of Bacteriology, Toyama Institute of Health, 17-1 Nakataikoyama, 939-0363 Imizu-city, Toyama, Japan. ${ }^{2}$ Department of Bacteriology I, National Institute of Infectious Diseases, 1-23-1 Toyama, Shinjuku-ku, 162-8640 Tokyo, Japan.

Received: 11 August 2020 Accepted: 8 July 2021

Published online: 17 July 2021

References

1. Fraser DW, Tsai TR, Orenstein W, Parkin WE, Beecham HJ, Sharrar RG, et al. Legionnaires' disease: Description of an epidemic of pneumonia. N Engl J Med. 1977;297:1189-97.

2. Parte AC. LPSN — List of Prokaryotic names with Standing in Nomenclature (bacterio.net), 20 years on. Int J Syst Evol Microbiol. 2018;68:1825-9. doi: https://doi.org/10.1099/ijsem.0.002786. https://www.bacterio.net/genus/ legionella. Accessed 10 Feb 2021.

3. Mercante JW, Winchell JM. Current and emerging Legionella diagnostics for laboratory and outbreak investigations. Clin Microbiol Rev. 2015;28:95-133.

4. Cordes LG, Wiesenthal AM, Gorman GW, Phair JP, Sommers HM, Brown A, et al. Isolation of Legionella pneumophila from hospital shower heads. Ann Intern Med. 1981;94:195-7. 
5. Hlady WG, Mullen RC, Mintz CS, Shelton BG, Hopkins RS, Daikos GL. Outbreak of Legionnaire's disease linked to a decorative fountain by molecular epidemiology. Am J Epidemiol. 1993;138:555-62.

6. Ito I, Naito J, Kadowaki S, Mishima M, Ishida T, Hongo T, et al. Hot spring bath and Legionella pneumonia: An association confirmed by genomic identification. Intern Med. 2002;41:859-63.

7. Keller DW, Hajjeh R, DeMaria A, Fields BS, Pruckler JM, Benson RS, et al. Community outbreak of Legionnaires' disease: An investigation confirming the potential for cooling towers to transmit Legionella species. Clin Infect Dis. 1996:22:257-61.

8. Arnow PM, Chou T, Weil D, Shapiro EN, Kretzschmar C. Nosocomial Legionnaires' disease caused by aerosolized tap water from respiratory devices. J Infect Dis. 1982;146:460-7.

9. National Institute of Infectious Diseases and Tuberculosis and Infectious Diseases Control Division, Ministry of Health, Labour and Welfare. Legionellosis, April 1999-July 2000. Infect Agents Surveill Rep. 2000;21:186-7. http://idsc.nih.go.jp/iasr/21/247/tpc247.html. Accessed 10 Feb 2021.

10. Kanatani J, Isobe J, Kimata K, Shima T, Shimizu M, Kura F, et al. Close genetic relationship between Legionella pneumophila serogroup 1 isolates from sputum specimens and puddles on roads, as determined by sequencebased typing. Appl Environ Microbiol. 2013;79:3959-66.

11. Sakamoto R, Ohno A, Nakahara T, Satomura K, Iwanaga S, Kouyama Y, et al. Legionella pneumophila in rainwater on roads. Emerg Infect Dis. 2009;15: 1295-7

12. Chen NT, Chen MJ, Guo CY, Chen KT, Su HJ. Precipitation increases the occurrence of sporadic Legionnaires' disease in Taiwan. PLoS One. 2014;9: e114337. doi:https://doi.org/10.1371/journal.pone.0114337.

13. van Heijnsbergen $E$, de Roda Husman AM, Lodder WJ, Bouwknegt M, Docters van Leeuwen AE, Bruin JP, et al. Viable Legionella pneumophila bacteria in natural soil and rainwater puddles. J Appl Microbiol. 2014;117: 882-90

14. Montagna MT, De Giglio O, Cristina ML, Napoli C, Pacifico C, Agodi A, et al. Evaluation of Legionella air contamination in healthcare facilities by different sampling methods: An Italian multicenter study. Int J Environ Res Public Health. 2017;14(7). https://doi.org/10.3390/ijerph14070670.

15. Conza L, Pagani SC, Gaia V. Presence of Legionella and free-living amoebae in composts and bioaerosols from composting facilities. PLoS One. 2013; 8(7):e68244. doi:https://doi.org/10.1371/journal.pone.0068244.

16. Wiik R, Krøvel AV. Necessity and effect of combating Legionella pneumophila in municipal shower systems. PLoS One. 2014;9(12):e114331. doi:https://doi. org/10.1371/journal.pone.0114331.

17. Steinert M, Emödy L, Amann R, Hacker J. Resuscitation of viable but nonculturable Legionella pneumophila Philadelphia JR32 by Acanthamoeba castellanii. Appl Environ Microbiol. 1997;63(5):2047-53.

18. Conza L, Casati S, Gaia V. Detection limits of Legionella pneumophila in environmental samples after co-culture with Acanthamoeba polyphaga. BMC Microbiol. 2013;13:49. doi:https://doi.org/10.1186/1471-2180-13-49.

19. Borthong J, Omori R, Sugimoto C, Suthienkul O, Nakao R, Ito K. Comparison of database search methods for the detection of Legionella pneumophila in water samples using metagenomic analysis. Front Microbiol. 2018:9:1272. doi:https://doi.org/10.3389/fmicb.2018.01272.

20. Fujiyoshi S, Tanaka D, Maruyama F. Transmission of airborne bacteria across built environments and its measurement standards: a review. Front Microbiol. 2017;8:2336. doi:https://doi.org/10.3389/fmicb.2017.02336.

21. Edagawa A, Kimura A, Kawabuchi-Kurata T, Adachi S, Furuhata K, Miyamoto $H$. Investigation of Legionella contamination in bath water samples by culture, amoebic co-culture, and real-time quantitative PCR methods. Int J Environ Res Public Health. 201519;12:13118-30

22. Zhen $H$, Han T, Fennell DE, Mainelis G. Release of free DNA by membraneimpaired bacterial aerosols due to aerosolization and air sampling. Appl Environ Microbiol. 2013;79:7780-9.

23. Sakamoto R. Legionnaire's disease, weather, and climate. Bull World Health Organ. 2015;93:435-6.

24. National Institute of Infectious Diseases and Tuberculosis and Infectious Diseases Control Division, Ministry of Health, Labour and Welfare. Legionellosis, January 2003-September 2008, Japan. Infect Agents Surveill Rep. 2008;29:327-8. http://idsc.nih.go.jp/iasr/29/346/tpc346.html. Accessed 10 Feb 2021.

25. Ozeki Y, Yamada F, Saito A, Kishimoto T, Tanno S, Nakamura Y. Seasonal patterns of legionellosis in Saitama, 2005-2009. Jpn J Infect Dis. 2012;65: 330-3.
26. Amemura-Maekawa J, Kura F, Chida K, Ohya H, Kanatani J, Isobe J, et al. Legionella pneumophila and other Legionella species isolated from legionellosis patients in Japan between 2008 and 2016. Appl Environ Microbiol. 2018:84:e00721-18. doi:https://doi.org/10.1128/AEM.00721-18.

27. Kenagy $E$, Priest PC, Cameron CM, Smith D, Scott P, Cho V, et al. Risk factors for Legionella longbeachae Legionnaires' disease, New Zealand. Emerg Infect Dis. 2017;23:1148-54.

28. Lee JS, Shin YK, Yoon JH, Takeuchi M, Pyun YR, Park YH. Sphingomonas aquatilis sp. nov., Sphingomonas koreensis sp. nov., and Sphingomonas taejonensis sp. nov., yellow-pigmented bacteria isolated from natural mineral water. Int J Syst Evol Microbiol. 2001;51:1491-8.

29. Kim SJ, Moon JY, Lim JM, Ahn JH, Weon HY, Ahn TY, et al. Sphingomonas aerophila sp. nov. and Sphingomonas naasensis sp. nov., isolated from air and soil, respectively. Int J Syst Evol Microbiol. 2014;64:926-32.

30. Zhu L, Si M, Li C, Xin K, Chen C, Shi X, et al. Sphingomonas gei sp. nov., isolated from roots of Geum aleppicum. Int J Syst Evol Microbiol. 2015;65: 1160-6.

31. Barben J, Hafen G, Schmid J, Swiss Paediatric Respiratory Research Group. Pseudomonas aeruginosa in public swimming pools and bathroom water of patients with cystic fibrosis. J Cyst Fibros. 2005:4:227-31.

32. Nakamoto S, Sakamoto M, Sugimura K, Honmura Y, Yamamoto Y, Goda N, et al. Environmental distribution and drug susceptibility of Achromobacter xylosoxidans isolated from outdoor and indoor environments. Yonago Acta Med. 2017;60:67-70

33. Ducret A, Chabalier M, Dukan S. Characterization and resuscitation of 'nonculturable' cells of Legionella pneumophila. BMC Microbiol. 2014;14:3. doi: https://doi.org/10.1186/1471-2180-14-3.

34. Dietersdorfer E, Kirschner A, Schrammel B, Ohradanova-Repic A, Stockinger $\mathrm{H}$, Sommer R, et al. Starved viable but non-culturable (VBNC) Legionella strains can infect and replicate in amoebae and human macrophages. Water Res. 2018;141:428-38.

35. García MT, Jones S, Pelaz C, Millar RD, Abu Kwaik Y. Acanthamoeba polyphaga resuscitates viable non-culturable Legionella pneumophila after disinfection. Environ Microbiol. 2007;9:1267-77.

36. Greub G, Raoult D. Microorganisms resistant to free-living amoebae. Clin Microbiol Rev. 2004;17:413-33.

37. Chang CW, Chou FC. Assessment of bioaerosol sampling techniques for viable Legionella pneumophila by ethidium monoazide quantitative PCR Aerosol Sci Technol. 2011;45:343-51.

38. Ministry of Land, Infrastructure, Transport and Tourism. National road/street traffic situation survey. 2015. https://www.mlit.go.jp/road/census/h27/index. html. Accessed 10 Feb 2021. (In Japanese.).

39. Walsh PS, Metzger DA, Higuchi R. Chelex 100 as a medium for simple extraction of DNA for PCR-based typing from forensic material. Biotechniques. 1991;10:506-13.

40. Furuhata K, Okabe Y, Dogasaki C, Hara M, Fukuyama M. Isolation of Legionella spp. from soil in Japan. Bokin Bobai. 2002;30:555-61. (In Japanese.).

41. Morimoto Y. Usefulness of selection of Legionella by colony appearance. Jpn J Environ Infect. 2010;25:8-14. (In Japanese.).

42. Ratcliff RM. Sequence-based identification of Legionella. Methods Mol Biol. 2013;954:57-72.

43. Bolyen E, Rideout JR, Dillon MR, Bokulich NA, Abnet CC, Al-Ghalith GA, et al. Reproducible, interactive, scalable, and extensible microbiome data science using QIIME 2. Nat Biotechnol. 2019;37:852-7.

44. Callahan BJ, McMurdie PJ, Rosen MJ, Han AW, Johnson AJ, Holmes SP. DADA2: High-resolution sample inference from Illumina amplicon data. Nat Methods. 2016;13:581-3.

45. Katoh K, Misawa K, Kuma K, Miyata T. MAFFT: a novel method for rapid multiple sequence alignment based on fast Fourier transform. Nucleic Acids Res. 2002;30:3059-66.

46. Price MN, Dehal PS, Arkin AP. FastTree 2 - approximately maximumlikelihood trees for large alignments. PLoS One. 2010;5:e9490. doi:https://doi. org/10.1371/journal.pone.0009490.

47. Bokulich NA, Kaehler BD, Rideout JR, Dillon M, Bolyen E, Knight R, et al. Optimizing taxonomic classification of marker-gene amplicon sequences with QIIME 2's q2-feature-classifier plugin. Microbiome. 2018;6:90. doi: https://doi.org/10.1186/s40168-018-0470-z.

48. McDonald D, Price MN, Goodrich J, Nawrocki EP, DeSantis TZ, Probst A, et al. An improved Greengenes taxonomy with explicit ranks for ecological and evolutionary analyses of bacteria and archaea. ISME J. 2012:6:610-8. doi: https://doi.org/10.1038/ismej.2011.139. 
49. Jeong J, Yun K, Mun S, Chung WH, Choi SY, Nam YD, et al. The effect of taxonomic classification by full-length 165 rRNA sequencing with a synthetic long-read technology. Sci Rep. 2021;11:1727. doi:https://doi.org/1 0.1038/s41598-020-80826-9.

50. Faith DP. Conservation evaluation and phylogenetic diversity. Biol Cons. 1992;61:1-10.

51. Lozupone CA, Hamady M, Kelley ST, Knight R. Quantitative and qualitative beta diversity measures lead to different insights into factors that structure microbial communities. Appl Environ Microbiol. 2007;73:1576-85.

52. Segata N, lzard J, Waldron L, Gevers D, Miropolsky L, Garrett WS, et al. Metagenomic biomarker discovery and explanation. Genome Biol. 2011;12: R60. doi:https://doi.org/10.1186/gb-2011-12-6-r60.

53. Benjamini Y, Hochberg Y. Controlling the false discovery rate: a practical and powerful approach to multiple testing. J R Stat Soc Ser B. 1995:57:289-300.

54. Japan Meteorological Agency. Past weather data search. 2019. http://www. data.jma.go.jp/obd/stats/etrn/index.php. Accessed 10 Feb 2021. (In Japanese.).

\section{Publisher's Note}

Springer Nature remains neutral with regard to jurisdictional claims in published maps and institutional affiliations.

Ready to submit your research? Choose BMC and benefit from:

- fast, convenient online submission

- thorough peer review by experienced researchers in your field

- rapid publication on acceptance

- support for research data, including large and complex data types

- gold Open Access which fosters wider collaboration and increased citations

- maximum visibility for your research: over $100 \mathrm{M}$ website views per year

At BMC, research is always in progress.

Learn more biomedcentral.com/submissions 